\title{
CAPITAL HUMANO E OBTENÇÃO DE INFORMAÇÕES TÉCNICAS NA AGRICULTURA: PERFIL E DIFERENÇAS REGIONAIS A PARTIR DOS DADOS DO CENSO AGROPECUÁRIO DE 2017
}

Júnia Cristina P. R. da Conceição²

\section{INTRODUÇÃO}

O desenvolvimento da agricultura no Brasil só foi possível com a incorporação de inovaçôes tecnológicas no processo produtivo. Na visão de Wedekin (2019), esta continuará sendo uma diretriz importante. Essa diretriz somente será exitosa se existirem bases preestabelecidas, ancoradas em um aparato científico, para que o desenvolvimento ocorra de forma satisfatória.

Souza Filho et al. (2011), Alves (2012), Alves et al. (2013), Vieira Filho, Santos e Fornazier (2013) e Vieira Filho (2013) apontaram a existência de diferentes padróes de desenvolvimento agrícola entre as regiôes brasileiras. Neste sentido, propostas de políticas públicas que objetivem a adoção e a difusão de tecnologias não podem ser as mesmas para diferentes regiôes. As políticas públicas devem levar em consideração as diferenças regionais, sejam elas de origem produtiva, tecnológica ou referentes ao estoque de capital humano.

Na visão de Souza Filho et al. (2011), a decisão de adoção de inovaçôes tecnológicas é determinada também pela disponibilidade dos fatores de produção - além disso, as barreiras econômicas podem dificultar ou impedir a adoção de inovaçôes tecnológicas.

Torna-se importante ressaltar que, para o desenvolvimento da agricultura brasileira, as variáveis de capital humano são fundamentais. Na visão de Wedekin (2019), os investimentos em educação e capital humano serão essenciais para a agricultura no futuro. Dessa forma, percebe-se que a continuação do avanço tecnológico do campo exigirá a formação de agricultores que estejam aptos para a utilização e a adoção de tecnologias atuais e também para o desenvolvimento de tecnologias futuras.

A divulgação recente dos dados do censo agropecuário de 2017 oferece uma oportunidade para a investigação de como esse aparato técnico-científico está distribuído entre as regióes do país, do ponto de vista da oferta de capital humano. Nesse sentido, este trabalho pretende

1. DOI: http://dx.doi.org/10.38116/brua23art3

2. Técnica de planejamento e pesquisa na Diretoria de Estudos e Políticas Regionais, Urbanas e Ambientais (Dirur) do Ipea. 
fazer um diagnóstico da educação e da forma como os agricultores obtêm informação técnica nas regióes Norte, Nordeste, Sul, Sudeste e Centro-Oeste. O papel desempenhado pela assistência técnica e também pelas outras fontes para a obtenção de informações técnicas será verificado.

O trabalho está organizado da seguinte forma, além desta introdução. Na segunda parte, é realizada uma análise das variáveis de capital humano para a adoção de inovaçôes tecnológicas. Na terceira, analisam-se os dados do censo agropecuário de 2017, referentes ao capital humano para as Grandes Regióes do Brasil. Na quarta parte, são apresentados os principais resultados encontrados.

\section{CAPITAL HUMANO, EXTENSÃO RURAL E ADOÇÃO DE TECNOLOGIAS}

É reconhecida a importância do capital humano para o desenvolvimento da agricultura. O trabalho pioneiro de Schultz (1973), por exemplo, ressalta a importância da educação para o progresso e o desenvolvimento da agricultura.

O crescimento da produção agropecuária brasileira dependeu e continuará dependendo pesadamente de seu sistema de pesquisa. A pesquisa tecnológica liderada pela Empresa Brasileira de Pesquisa Agropecuária (Embrapa) é realizada em todo o país, englobando muitos produtos. Existe, também, um conjunto de institutos de pesquisas que desenvolvem tecnologias adaptadas às condiçóes regionais. Além disso, diversas instituiçóes públicas e privadas de pesquisa estão sendo criadas e se somam a outros renomados centros e institutos de larga experiência em desenvolvimento de tecnologias a fim de desenvolver pesquisa em diversas áreas.

Muitas escolas de engenharia agronômica e florestal, medicina veterinária, zootecnia e biologia existem no país. Teixeira, Clemente e Braga (2013) realçam a contribuição das universidades para o desenvolvimento do agronegócio brasileiro. Ademais, diversas tecnologias novas foram desenvolvidas pelo setor privado.

Schultz (1973) enfatiza que o capital humano pode atuar de duas maneiras sobre o desenvolvimento econômico: primeiro, pelo aumento da eficiência do próprio trabalhador (efeito produto); segundo, pela eficiência alocativa (efeito alocativo) dos fatores agregados de produção capital e trabalho.

Segundo Heckman, Lochner e Todd (2006), o capital humano é produtivo em virtude de seu efeito imediato sobre o incremento das habilidades dos trabalhadores. Assim, potencializa o uso dos recursos na sociedade, permitindo que as oportunidades sejam mais bem aproveitadas. Nesse sentido, o termo capital humano engloba as aptidóes e habilidades pessoais que permitem aos indivíduos gerar renda e que fundamentalmente dependem do sistema educacional (Becker, 1993; Schultz,1981).

Schultz (1981) mostrou que a qualidade da força de trabalho é uma importante variável econômica responsável pelo incremento da produtividade. Becker (1993), por sua vez, avançou em direção a uma teoria do capital humano e forneceu evidências empíricas, comprovando que os investimentos em educação são tâo importantes quanto os investimentos em outras formas de capital. Os estudos de Schultz (1981) e Becker (1993) vão na direção das conclusóes de Barro (1990) no sentido de colocar o capital humano como uma importante força explicativa do crescimento econômico endógeno.

Um aspecto importante da teoria desenvolvida por Becker (1993) e Schultz (1981) é o fato de que os investimentos em conhecimento, habilidades e saúde não apenas beneficiam 
os indivíduos, mas incrementam a produtividade de uma economia por meio da melhoria das condições do capital humano. Isso pode ocorrer a partir dos efeitos exercido pelo capital humano na capacidade de inovação, de difusão e de adoção de novas tecnologias (Chen, 1995).

O papel da extensão rural também é importante para o processo de adoção de tecnologias na área agrícola, visto que, em muitos países, as informaçōes sobre inovaçóes agrícolas são fornecidas por agências governamentais e privadas de extensão rural - a extensão rural constitui um canal de extrema relevância na disponibilização e no acesso à informação no campo. Nas condiçôes da agricultura brasileira, os serviços de assistência técnica devem contribuir tanto para a adoçáo de tecnologias apropriadas como para propor o desenvolvimento de atividades agrícolas viáveis economicamente, além de realizar a capacitação dos agricultores familiares para a inovação.

Souza Filho, Rosa e Vinholis (2010) afirmam que, em algumas situaçóes, são adotadas recomendaçóes que, dada a insuficiência de recursos dos produtores, são aplicadas de forma incompleta e não sistemática. Esse fato pode gerar ineficiências. É necessário reconhecer que a funçáo de capacitaçáo e aconselhamento sobre o que produzir, diante de cenários econômicos desfavoráveis, exige que o extensionista rural também possua conhecimento de mercado, uma vez que o desconhecimento pode acarretar o desenho e a implantaçáo de projetos inadequados para as condiçôes de mercado e/ou socioeconômicas locais.

Com relação ao serviço de extensão, apesar da grande capilaridade do serviço público, sua capacidade de atender ao conjunto de demandas deteriorou-se. Em algumas regióes do país, a presença de novos atores do setor privado passou a desempenhar essas funçóes (Souza Filho, Rosa e Vinholis, 2010). De fato, essa constataçáo já havia sido feita na década de 1990 - Alves e Contini (1992) já haviam chamado a atenção para isso. Os autores ressaltaram que a extensão privada aumentou sua importância à medida que o desenvolvimento foi sendo conquistado e é muito especializada em transferência de tecnologia.

Ainda segundo Souza Filho, Rosa e Vinholis (2010), no Brasil, nas regiōes Centro-Oeste, Sudeste e Sul, a presença da extensão privada, representada por firmas de insumos modernos, agroindústrias, cooperativas e organizaçôes especializadas em planejamento, é uma realidade. Assim, a extensão pública deixa de ser o principal agente de transferência de tecnologia e a extensão privada passa a ser preponderante, principalmente em regiōes que desenvolvem uma agricultura avançada.

Além disso, Conceição, Araújo e Conceição (2006) salientam a existência de outras fontes, tais como livros, revistas e materiais impressos adicionais, que também podem ser importantes vetores para o acesso a informaçôes técnicas. Os mesmos autores, com o intuito de obter uma orientação quanto a variáveis que pudessem auxiliar no aprimoramento da habilidade dos agricultores, estimaram um modelo procurando relacionar a influência das variáveis educação, extensão privada, extensão pública, experiência e rádio na eficiência técnica. O modelo incluiu, além das variáveis citadas, a variável fontes alternativas de informação (rádio), que foi importante na explicação dos níveis de eficiência técnica encontrados.

De acordo com o estudo, os produtores que tiveram maior contato com os serviços de extensão privada apresentaram níveis de eficiência técnica maiores. Isso evidencia um importante papel que a extensão privada desempenhou no que se refere à agricultura comercial brasileira produtora de grãos. Os produtores, ao adquirirem os insumos, possivelmente tiveram acesso a informaçóes, e isso repercutiu no nível de eficiência. 
A disponibilização do conhecimento por meio da tecnologia da informação continua a ganhar espaço na agricultura. Esse tipo de tecnologia afeta a forma de gestão da propriedade rural ao facilitar a busca, o acesso, o armazenamento e a disseminação de informaçóes, o que melhora as condiçôes de tomada de decisão do produtor.

Além de software e portais sobre o agronegócio, o conjunto de tecnologias da informação inclui equipamentos para o armazenamento de dados de manejo da lavoura e rebanho, canais de televisão e estrutura de telecomunicações (Machado, 2007), e aplicativos como os de seguro rural (PSR) e zoneamento climático (Zarc) do Ministério da Agricultura, a fim de orientar os agricultores e facilitar o acesso às políticas. Francisco e Pino (2004) verificaram que a probabilidade de adoção de tecnologias em propriedades rurais do estado de São Paulo ocorria com maior frequência naquelas que tinham uma administraçáo mais profissionalizada e um nível tecnológico mais elevado (tanto na produção quanto na administração).

É importante ressaltar que os agricultores familiares têm maiores dificuldades para superar as deficiências na provisão dos serviços públicos de assistência técnica e educação rural. Fatores tais como nível educacional, formação profissional, capitalização e condiçôes de acesso aos mercados limitam o seu acesso à assistência técnica privada.

Em algumas regiôes brasileiras e em alguns segmentos da agricultura, a assistência técnica passou a ser oferecida por um conjunto maior de atores, crescendo a heterogeneidade em termos de características e formas de organizaçáo. Entre elas, podem ser citadas as que detêm conhecimento tecnológico em genética, agroquímicos, medicamentos para animais, equipamentos; grandes empresas de abate/processamento, que, embora ainda timidamente, estabelecem parcerias com pecuaristas; e empresas de consultoria formadas por profissionais que oferecem serviços técnicos, inclusive em gestão das propriedades rurais e unidades de abate/processamento (Souza Filho, Rosa e Vinholis, 2010).

Alguns autores acreditam que, mesmo em grupos de produtores com maior nível de escolaridade, a função da extensão rural é determinante. Doye et al. (2000), por exemplo, verificaram a importância do trabalho dos consultores e veterinários como um complemento às habilidades e aos esforços pessoais dos produtores. Segundo os autores, não se discute a relevância desse canal para o acesso à informação de qualidade na agricultura, mas há o aparecimento de outras fontes de informação técnica.

O efeito de diferentes variáveis no processo de adoção e difusão depende, como já salientado, do contexto geral no qual a inovação é introduzida. O entorno econômico pode ser determinante. É exatamente por esse motivo que a análise regional é importante.

\section{ANÁLISE DOS DADOS DO CENSO}

Os dados do Censo Agropecuário 2017, recentemente divulgados, oferecem uma oportunidade importante para o mapeamento de como estão distribuídas as variáveis de capital humano entre as Grandes Regiōes do país. Além dessas variáveis (educação e assistência técnica), analisaram-se também aquelas referentes à origem e à forma das orientaçóes técnicas recebidas.

\subsection{Nível de escolaridade}

O nível de escolaridade é uma variável-chave para o desenvolvimento: ele dará o suporte, do ponto de vista do capital humano, para que as orientaçóes técnicas possam ser absorvidas e utilizadas corretamente, proporcionando, assim, o desenvolvimento. Essa variável foi analisada entre as Grandes Regióes do país para se ter uma ideia de como está o nível de 
escolaridade entre elas, indicando quais regiōes têm maior potencialidade de desenvolvimento e incorporação de inovaçóes tecnológicas.

A tabela 1 apresenta o nível de escolaridade do produtor por Grande Regiáo (Norte, Nordeste, Sul, Sudeste e Centro-Oeste). O nível de escolaridade é bem distinto entre as regiōes brasileiras. No Norte, $79,6 \%$ sabem ler e escrever. No Nordeste, esse percentual é de $61,8 \%$. Nas regióes Sudeste e Sul, por sua vez, o percentual é de 90,0\% e 95,8\% - no Centro-Oeste, é de $91,2 \%$. Verifica-se, dessa maneira, que o percentual de agricultores com capacidade de ler e escrever é bem inferior nas regiôes Norte e Nordeste quando comparado com as demais regiôes.

Outro ponto importante a se destacar é o alto índice de agricultores que não sabem ler nem escrever no Norte e no Nordeste - 20,4\% e 38,2\%, respectivamente. Esse percentual é bem inferior nas demais regióes do Brasil: 10,0\%, 4,2\% e 8,8\% no Sudeste, no Sul e no Centro-Oeste, respectivamente.

Entre os níveis educacionais, o maior percentual em quase todas as regióes refere-se ao nível educacional regular do ensino fundamental de primeiro grau. Somente na região Centro-Oeste o nível educacional regular de ensino médio de segundo grau apresenta o maior percentual.

O nível educacional de graduação também apresenta um percentual pequeno em quase todas as regióes. Novamente, o Centro-Oeste exibe um percentual superior aos demais para esse nível de escolaridade. O nível de mestrado ou doutorado mostra um percentual bem pequeno, ou seja, é bastante raro para os agricultores em todas as regiôes do Brasil.

Quando a análise é feita levando-se em consideração as tipologias agricultura familiar e agricultura não familiar, os resultados apresentam algumas constataçôes interessantes. Por exemplo, o percentual de agricultores que não sabem ler nem escrever é maior para os agricultores familiares nas regióes Norte e Nordeste, quando comparados com os não familiares nessas mesmas regiôes. Nas demais, o percentual também é inferior para a agricultura familiar, mas a diferença é bem menor.

Outro ponto importante a ser destacado é o fato de o nível de escolaridade mais elevado (graduação) exibir um percentual maior entre os agricultores não familiares em todas as regióes.

A distribuição da escolaridade entre as regiōes demonstra que a possibilidade de diminuição das heterogeneidades produtivas é difícil, principalmente porque há também uma heterogeneidade da distribuição da educação - as regióes Norte e Nordeste são as que apresentam uma pior distribuição. Esse fato pode acentuar ainda mais as disparidades produtivas regionais. 


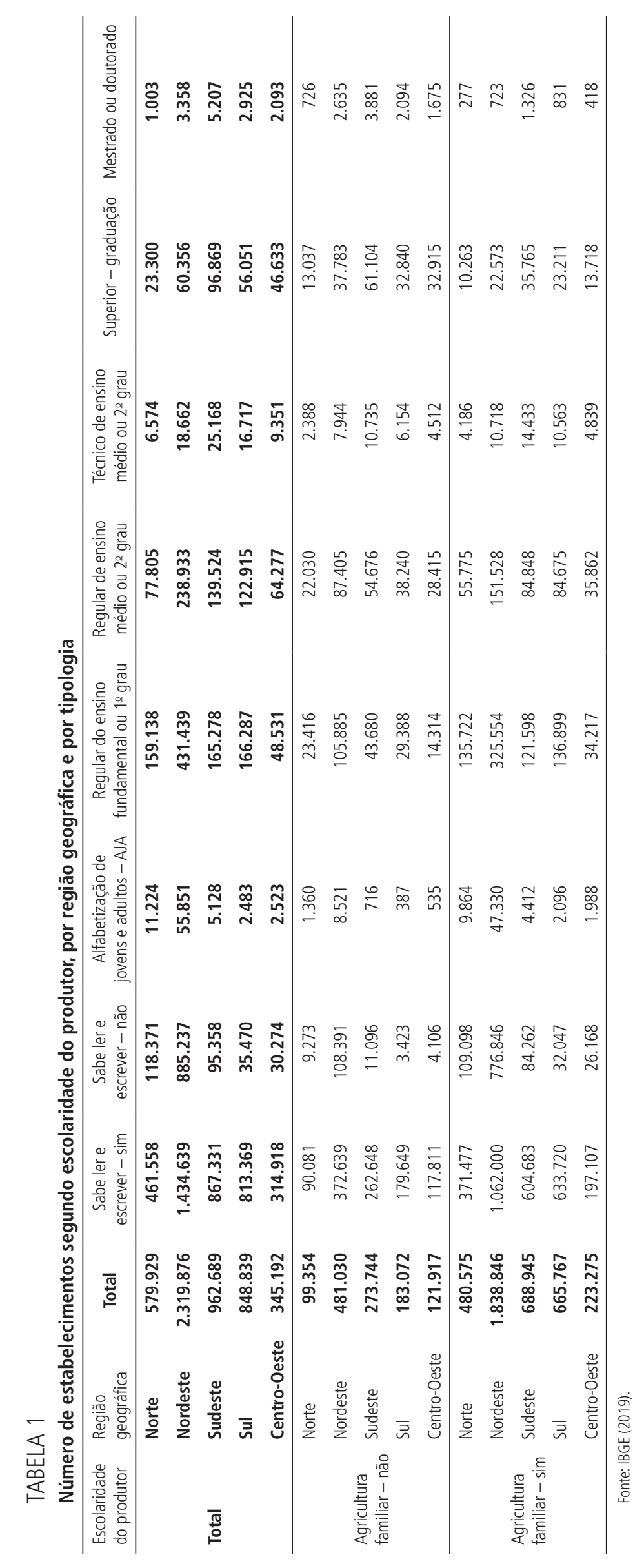




\subsection{Orientação técnica entre as regiões}

Além da escolaridade, a obtenção de orientações técnicas também é importante para o desenvolvimento da agricultura. Nesse sentido, fez-se uma análise entre as regióes para verificar se os estabelecimentos recebem ou não orientações técnicas (tabela 2).

A questão da orientação técnica, também importante para que o produtor adquira conhecimentos técnicos, foi analisada com um recorte regional. É possível perceber, na tabela 2, que, no Brasil, 20,1\% dos estabelecimentos recebem orientação técnica. O percentual de estabelecimentos classificados como de agricultores familiares que recebem orientação técnica é inferior ao dos agricultores não familiares. No caso dos agricultores familiares, esse percentual é de $18,7 \%$ e, no dos náo familiares, de $27,0 \%$.

TABELA 2

Número de estabelecimentos, por tipologia, que recebem ou não orientação técnica, por Grande Região

\begin{tabular}{|c|c|c|c|c|c|c|c|c|c|}
\hline \multirow{2}{*}{$\begin{array}{l}\text { Brasil e } \\
\text { Grande Região }\end{array}$} & \multicolumn{3}{|c|}{ Agricultura } & \multicolumn{3}{|c|}{ Agricultura familiar - não } & \multicolumn{3}{|c|}{ Agricultura familiar - sim } \\
\hline & Total & Recebem & Não recebem & Total & Recebem & Não recebem & Total & Recebem & Não recebem \\
\hline Brasil & 5.073 .324 & 1.025 .443 & 4.047 .881 & 1.175 .916 & 317.125 & 858.791 & 3.897 .408 & 708.318 & 3.189 .090 \\
\hline Norte & 580.613 & 60.351 & 520.262 & 100.038 & 17.953 & 82.085 & 480.575 & 42.398 & 438.177 \\
\hline Nordeste & 2.322 .719 & 190.804 & 2.131 .915 & 483.873 & 55.975 & 427.898 & 1.838 .846 & 134.829 & 1.704 .017 \\
\hline Sudeste & 969.415 & 277.593 & 691.822 & 280.470 & 108.628 & 171.842 & 688.945 & 168.965 & 519.980 \\
\hline Sul & 853.314 & 414.645 & 438.669 & 187.547 & 89.246 & 98.301 & 665.767 & 325.399 & 340.368 \\
\hline Centro-Oeste & 347.263 & 82.050 & 265.213 & 123.988 & 45.323 & 78.665 & 223.275 & 36.727 & 186.548 \\
\hline
\end{tabular}

Fonte: IBGE (2019).

Quando a análise é feita em nível regional, algumas diferenças são identificadas. As regiōes Norte e Nordeste são as que apresentam o menor percentual de estabelecimentos que recebem orientação técnica. Esse percentual é ainda menor para os de agricultores familiares, de $91,0 \%$ e 92,0\%, respectivamente, para os que não recebem orientação técnica.

Nas regiôes Sudeste, Sul e Centro-Oeste, o percentual de estabelecimentos que recebem orientação técnica é bem superior, aproximadamente $28,0 \%, 48,0 \%$ e 23,0\%, respectivamente. Dessa forma, é possível perceber, no Sul, a importância da orientação técnica: quase metade dos estabelecimentos a recebe. No Sudeste e no Centro-Oeste, o percentual de estabelecimentos que recebem orientação técnica é superior para os de agricultores não familiares. Na região Sul, o comportamento é distinto. Embora o percentual dos estabelecimentos de agricultores não familiares seja maior, a diferença é bem pequena.

Realizou-se também uma investigação da relação existente entre as variáveis orientação técnica e escolaridade. A ideia consistiu em verificar qual era o nível de escolaridade dos produtores responsáveis pelos estabelecimentos que recebem orientação técnica vis-à-vis os que não a recebem, em nível regional.

Os resultados, apresentados na tabela 3, indicam que os estabelecimentos em que os agricultores possuem algum nível educacional têm maior acesso às orientaçóes técnicas. Isso é verdadeiro para todas as regiôes do Brasil. Isto é, a obtenção de orientaçóes técnicas é buscada, principalmente, por estabelecimentos com agricultores que têm pelo menos o nível de ensino equivalente ao regular do ensino fundamental. Existem, entretanto, algumas singularidades regionais que podem ser ressaltadas. 


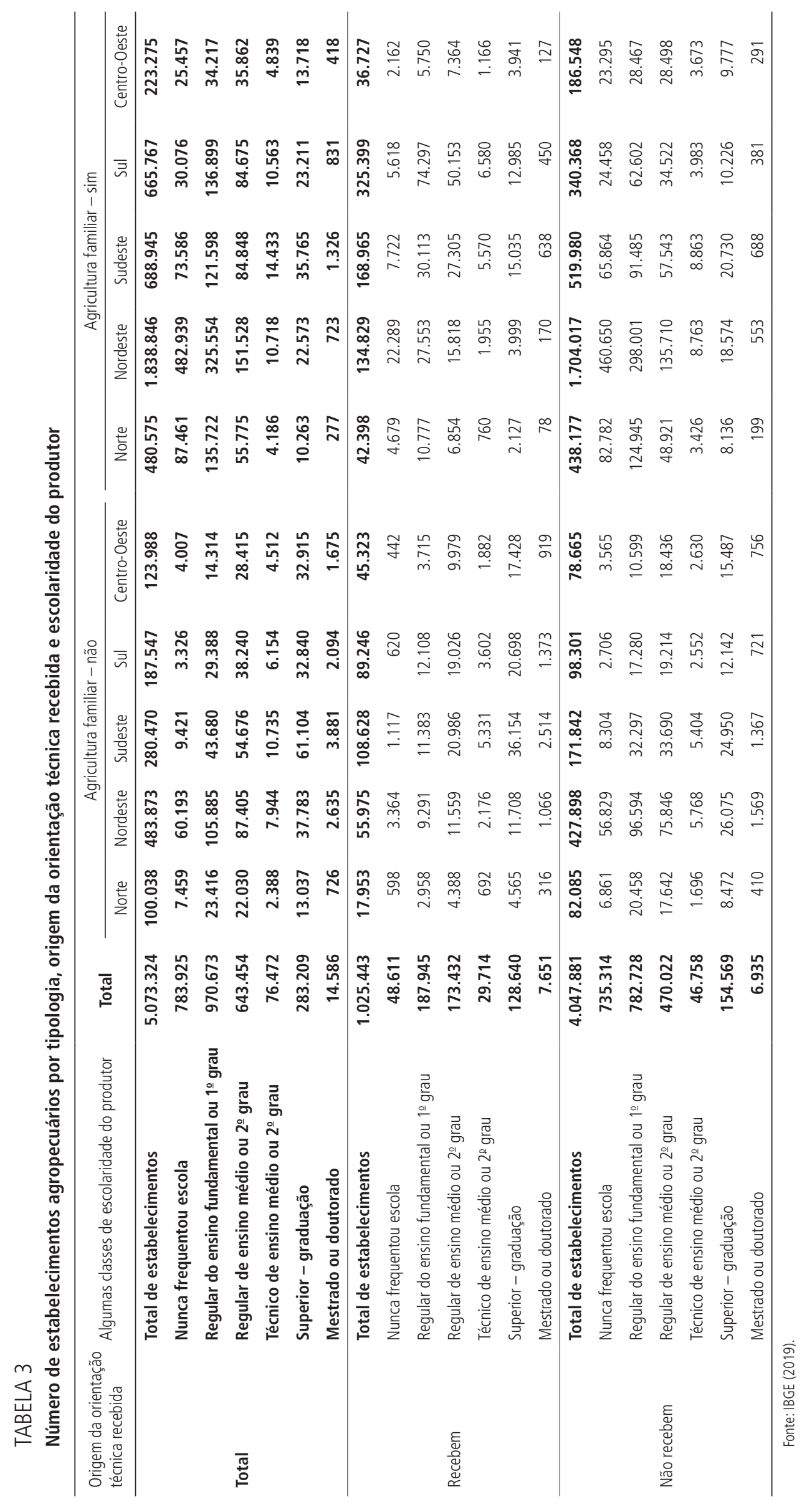


Nas regiōes Norte, Nordeste e Sul, o maior percentual de estabelecimentos agropecuários que recebem orientações técnicas - 22,8\%, 19,3\% e 20,8\%, respectivamente - tem o nível educacional regular do ensino fundamental. No Sudeste, o maior percentual $(17,4 \%)$ refere-se aos agricultores com nível educacional referente ao regular do ensino médio. Já Centro-Oeste, o maior percentual (26,0\%) está entre aqueles que possuem o nível superior (graduação).

A análise feita entre os estabelecimentos de agricultores familiares e não familiares também mostra resultados interessantes.

Os estabelecimentos gerenciados por agricultores não familiares do Centro-Oeste e do Sudeste cujo responsável tem nível educacional superior (graduação) são os que apresentam o maior percentual (33,3\% e 38,5\%) de obtenção de orientação técnica. Nas demais regiôes, o percentual de estabelecimentos cujo responsável recebe orientaçóes técnicas e que tem nível de educação superior (graduação) é menor, mas é ainda significativo.

No caso dos estabelecimentos administrados por agricultores familiares, o nível educacional é menor - o regular do ensino fundamental apresenta o maior percentual de estabelecimentos que têm orientaçôes técnicas para todas as regiōes, com exceção do Centro-Oeste, onde o percentual maior é para o nível educacional regular do ensino médio.

No que se refere à origem da orientação técnica, percebe-se uma diferença entre as regiốes. A tabela 4 expóe os resultados encontrados. Na regiấo Norte, apenas 10,0\% recebem orientação técnica e $89,0 \%$ não a recebem. Dos que a recebem, a grande maioria $(66,7 \%)$ conta com o governo, e $24,0 \%$ têm orientação própria; as cooperativas representam apenas $3,4 \%$ da origem das orientações técnicas recebidas.

$\mathrm{Na}$ região Nordeste, apenas $8,2 \%$ dos estabelecimentos recebem orientação técnica; $91,8 \%$ não a recebem. Daqueles que a recebem, a maioria (60\%) conta com orientação do governo e $23 \%$ têm orientação técnica própria ou do próprio produtor.

No Sudeste, o percentual de estabelecimentos que recebem orientação técnica é maior, $28,6 \%$. Na maioria (41,5\%), a origem da orientação é própria ou vem do governo (32,0\%). As cooperativas apresentam uma participação de $23,0 \%$, bem superior à sua participação nas regiốes Norte e Nordeste. Ainda no Sudeste, 71,4\% não recebem orientação técnica.

A regiāo Sul, por seu turno, mostra um comportamento distinto: o percentual de estabelecimentos que recebem orientação técnica é bem superior ao das demais regiôes, $48,6 \%$. As cooperativas representam uma participação de $37,0 \%$ da origem das informações técnicas recebidas. Além disso, a participação das empresas integradoras também é importante nessa região: 26,6\%.

$\mathrm{Na}$ região Centro-Oeste, 23,6\% recebem orientação técnica - desse total, a maioria da orientação técnica recebida é própria $(53,5 \%)$. As cooperativas têm uma participação de $16 \%$ e as empresas integradoras, de $6,0 \%$.

Quando a análise é feita levando-se em consideração a tipologia da agricultura, verifica-se que o número de estabelecimentos de agricultura familiar que recebem orientação técnica é inferior ao de estabelecimentos de agricultura não familiar.

Outro ponto a ser observado é que o percentual de estabelecimentos de agricultura familiar e não familiar que recebem orientaçôes técnicas é diferenciado entre as regiōes - o de estabelecimentos de agricultura não familiar que recebem orientação técnica é superior ao de estabelecimentos de agricultura familiar, no Brasil e em quase todas as regióes. A única exceção é a regiâo Sul, onde o percentual maior é para os estabelecimentos de agricultura familiar. 


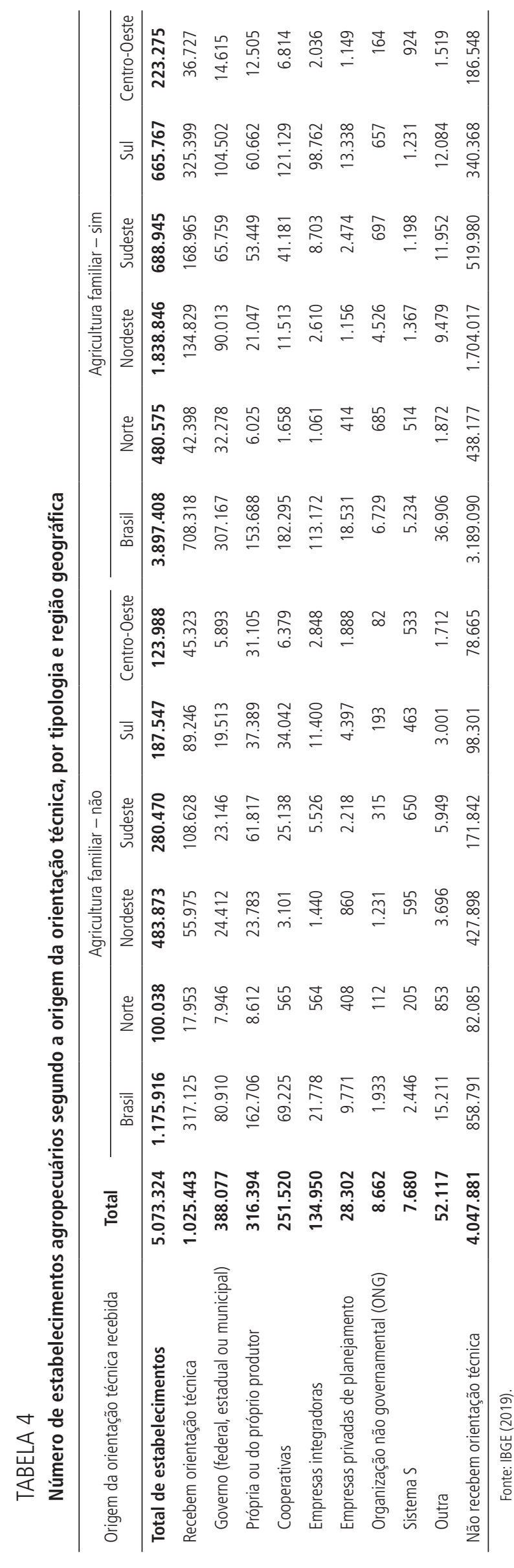


A forma de obtenção de orientaçôes técnicas também apresenta resultados interessantes (tabela 5). Um primeiro ponto a ser destacado é que, no Brasil, 74,0\% dos estabelecimentos recebem orientaçôes técnicas - a grande maioria pela televisão $(52,5 \%)$ e pelo rádio $(31,2 \%)$. A internet é o veículo utilizado por $12,1 \%$ dos estabelecimentos agropecuários, em nível de Brasil.

Do ponto de vista regional, aparecem algumas diferenças. A televisão e o rádio são os veículos de informação mais utilizados em todas as regióes. A internet, porém, aparece com maior destaque no Sudeste, no Sul e no Centro-Oeste, com 19,3\%, 22,9\% e 22,2\%, respectivamente. Nas regiōes Norte e Nordeste, esse percentual - 6,4\% e 5,1\%, respectivamente - é inferior à média do Brasil e ainda menor que o do Sudeste, do Sul e do Centro-Oeste.

Quando a análise é feita levando em consideração as tipologias agricultura familiar e não familiar, percebe-se que o percentual de estabelecimentos classificados como agricultura não familiar que não recebem orientaçóes técnicas é maior que o da agricultura familiar, principalmente nas regióes Sudeste, Sul e Centro-Oeste.

Outro ponto importante a ser ressaltado é o maior acesso à internet nos estabelecimentos de agricultores não familiares nas regióes Sul $(31,4 \%)$, Sudeste $(36,2 \%)$ e Centro-Oeste (34,4\%). Esses percentuais são de 14,4\%, 19,2\% e 15,5\% para os estabelecimentos de agricultura familiar nessas mesmas regióes.

Esse talvez possa ser um caminho a ser seguido, inclusive com o uso de aplicativos, os quais poderiam ser disponibilizados pelo Ministério da Agricultura. Dessa forma, haveria uma redução de custos relativos à extensão presencial - esse tipo de serviço presencial passaria a ser adicional. 


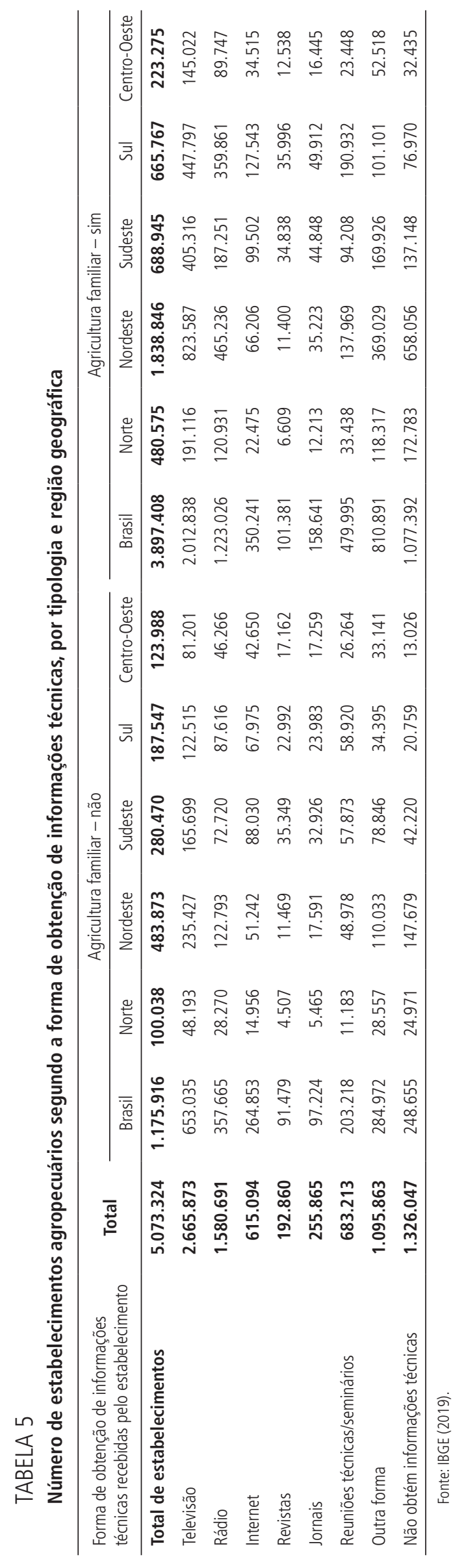




\section{CONSIDERAÇÕES FINAIS}

Este trabalho identificou que a desigualdade presente entre os produtores do meio rural no Brasil no que se refere ao capital humano (educação) e à forma de obtenção de informaçôes técnicas merece a atenção das políticas públicas. $\mathrm{O}$ acesso mais homogêneo aos fatores de produção e ao investimento na qualificação profissional dos produtores deveria ser objeto de programas públicos que pudessem transformar a realidade do campo brasileiro.

A análise regional oferece uma perspectiva de estudo mais próxima da realidade e proporciona a identificação de variáveis importantes para que o sucesso da política pública seja mais garantido.

A identificação da importância das cooperativas e das empresas integradoras no fornecimento de orientaçôes técnicas, por exemplo, sinaliza um caminho que poderá ser intensificado para que as orientaçóes técnicas cheguem aos agricultores. Essa, entretanto, não deverá ser a única alternativa para as regióes Norte e Nordeste, onde o papel do poder público ainda é o mais importante. No Sudeste, embora o poder público tenha uma grande participação, as cooperativas também aparecem com uma participaçáo importante como agentes de fornecimento de orientaçóes técnicas.

Outra questão importante que a análise regional mostra é que a informação sobre orientaçôes técnicas é obtida, principalmente, por meio da televisão e do rádio. Esses veículos de informação são ainda importantes em todas as regióes do Brasil. A internet, por sua vez, também mostrou ser uma forma de obtenção de orientaçôes técnicas. Essa importância, contudo, é maior nas regiôes Sul, Sudeste e Centro-Oeste e, principalmente, para a agricultura não familiar.

O conhecimento dessas diversidades entre as regióes e também entre os tipos de agricultura (familiar e não familiar) demonstra a necessidade de conhecimento da realidade para que a formulação de políticas públicas seja mais adequada e, assim, sua adoção leve a resultados eficazes. Caso contrário, não haverá eficiência e os resultados de implementação das políticas públicas também não terão êxito.

É preciso perceber que já houve avanços com o reconhecimento da agricultura familiar e também com a possibilidade de discussão de políticas territoriais e regionais, mas é preciso aperfeiçoar ainda mais o modelo agrícola brasileiro. A identificação do caráter heterogêneo do campo no Brasil, em suas diversas dimensóes, inclusive na tratada neste estudo, qual seja a dimensão referente ao capital humano, é a forma mais segura para a promoção do desenvolvimento rural.

A constatação da heterogeneidade do estoque de capital humano entre as regiōes pode comprometer o desenvolvimento da agricultura em locais onde esse capital é menor, principalmente no momento atual, em que o conhecimento passa a ser fundamental para que os avanços tecnológicos possam ser assegurados.

Nesse sentido, para que o desenvolvimento da agricultura no Brasil tenha uma distribuição mais homogênea entre as regiōes, faz-se necessária a adoção de políticas que levem em consideração as diversidades regionais existentes inclusive no que se refere ao estoque de capital humano. Isto é, as diferenças de capital humano entre as regiōes não são, por si só, um empecilho para o desenvolvimento da agricultura, mas devem ser levadas em consideração para que políticas públicas mais efetivas possam ser adotadas. 


\section{REFERÊNCIAS}

ALVES, E. Nosso problema de difusão de tecnologia. Revista de Política Agrícola, v. 21, n. 1, p. 3-4, 2012.

ALVES, E. R. de A.; CONTINI, E. A modernização da agricultura brasileira. ln: BRANDÃO, A. S. P. (Ed.). Os principais problemas da agricultura brasileira: análise e sugestôes. 2. ed. Brasília: Ipea, 1992.

ALVES, E. R. de A. et al. Fatos marcantes da agricultura brasileira. In: ALVES, E. R. de A.; SOUZA, G. da S. e; GOMES, E. G. (Ed.). A contribuição da Embrapa para o desenvolvimento da agricultura brasileira. Brasília: Embrapa, 2013.

ALVES, E. R. de A.; SILVA, R. C. Qual é o problema de transferência de tecnologia do Brasil e da Embrapa? In: ALVES, E. R. de A.; SOUZA, G. da S. e; GOMES, E. G. (Ed.). A contribuiçáo da Embrapa para o desenvolvimento da agricultura brasileira. Brasília: Embrapa. 2013.

BARRO, R. J. Government spending in a simple model of endogenous growth. Journal of Political Economy, v. 98, n. 5, p. 103-125, 1990.

BECKER, G. S. Human capital: a theoretical and empirical analysis, with special reference to education. 3. ed. London: University of Chicago Press, 1993.

CHEN, B.-L. Economic growth: Robert J. Barro and Xavier Sala-i-Martin, (McGraw-Hill, 1995), 539 pp. Journal of Economic Dynamics and Control, v. 21, n. 4-5, p. 895-898, 1995.

CONCEIÇÃO, J. C. P. R.; ARAÚJO, P. F. C.; CONCEIÇÃO, P. H. Z. Influência de variáveis representativas de capital humano na adoção de inovações tecnológicas na agricultura brasileira. In: CONGRESSO LATINO-AMERICANO DE SOCIOLOGIA RURAL, 7., 2006, Quito, Equador. Anais... Quito: Alasru, 2006.

DOYE, D. et al. Case studies of farmers' use of information systems. Review of Agricultural Economics, v. 22, n. 2, p. 566-585, 2000.

FRANCISCO, V. L. F. dos S.; PINO, F. A. Fatores que afetam o uso da internet no meio rural paulista. Agricultura em São Paulo, v. 51, n. 2, p. 27-36, jul./dez. 2004.

GOYAL, A.; GONZÁLEZ-VELOSA, C. Improving agricultural productivity and market efficiency in Latin America and the Caribbean: how ICTs can make a difference? Washington: World Bank, 2012. (LCSSD Occasional Paper Series on Food Prices, n. 68255).

HECKMAN, J. J.; LOCHNER, L. J.; TODD, P. E. Earnings equations and rates of return: the mincer equation and beyond. In: HANUSHEK, E.; WELCH, F. (Ed.). Handbook of the economics of education. Oxford: North-Holland, 2006. p. 307-458. v. 2.

IBGE - INSTITUTO BRASILEIRO DE GEOGRAFIA E ESTATÍSTICA. Censo agropecuário 2017: resultados definitivos. Rio de Janeiro: IBGE, 2019. Disponível em: <https://biblioteca. ibge.gov.br/visualizacao/periodicos/3096/agro_2017_resultados_definitivos.pdf>. Acesso em: 5 jun. 2020.

MACHADO, J. G. de C. F. Adoção da tecnologia da informação na pecuária de corte. 2007. Tese (Doutorado) - Universidade Federal de São Carlos, São Carlos, 2007.

SCHULTZ, T. W. O capital humano: investimentos em educação e em pesquisa. Rio de Janeiro: Zahar, 1973. 
Investing in people: the economics of population quality. London: University of California Press, 1981.

SOUZA FILHO, H. M. de et al. Condicionantes da adoção de inovaçôes tecnológicas na agricultura. Cadernos de Ciência e Tecnologia, v. 28, n. 1, p. 223-255, jan./abr. 2011.

SOUZA FILHO, H. M. de; ROSA, F. T.; VINHOLIS, M. de M. B. Análise da competitividade da cadeia produtiva da carne bovina do Estado de São Paulo. Informaçóes Econômicas, v. 40, n. 3, p. 16-28, 2010.

TEIXEIRA, E. C.; CLEMENTE, F.; BRAGA, M. J. a contribuição das universidades para o desenvolvimento da agricultura no Brasil. Revista de Economia e Agronegócio, v. 11, n. 1, p. 137-158, 2013.

VIEIRA FILHO, J. E. R. Grupos de eficiência tecnológica e desigualdade produtiva na agricultura brasileira. In: ALVES, E. R. de A.; SOUZA, G. da S. e; GOMES, E. G. (Ed.). A contribuiçáo da Embrapa para o desenvolvimento da agricultura brasileira. Brasília: Embrapa, 2013.

VIEIRA FILHO, J. E. R.; SANTOS, G. R. dos; FORNAZIER, A. Distribuiçáo produtiva e tecnológica da agricultura brasileira e sua heterogeneidade estrutural. Brasília: Ipea; Cepal, 2013. (Texto para Discussão, n. 54).

WEDEKIN, I. (Org.). Política agrícola no Brasil: o agronegócio na perspectiva global. São Paulo: WDK Agronegócio, 2019. 
